\title{
Contribución al estudio histórico de la brucelosis en Chile
}

\author{
Enrique Laval $R$.
}

\section{A contribution to historical understanding of brucellosis in Chile}

Junto a enfermedades infecciosas de las cuales se desconoce la época histórica en la que se iniciaron, ya que parecen vinculadas al origen mismo del hombre, existen otras, cuyo punto de procedencia y fecha de aparición parecen ser bien conocidos. Tal sería el caso de la brucelosis ${ }^{1}$.

Esta enfermedad "nació" a principio del siglo XIX en la isla centro mediterránea de Malta. Algunos de sus habitantes fallecían a consecuencia de un cuadro febril cuya causa permanecía ignorada y según las estadísticas de la época, enfermaban más mujeres que hombres.

Las tropas inglesas que ocupaban la isla, sufrían así mismo el embate de la infección, que ocasionaba la muerte a regular número de sus soldados. Ante esta situación, el gobierno inglés, en 1904, determinó el envío a la isla de una comisión investigadora, llamada Mediterraneam Fever Comission, constituida por varios médicos militares, presidida por David Bruce. En 1905, Zammit comprobó el papel epidemiológico desempeñado por las cabras, al demostrar que $50 \%$ de ellas sufría la enfermedad, Observó que los soldados que salían de los cuarteles y bebían leche de cabra contraían la enfermedad, mientras los que no hacían tal permanecían indemnes ${ }^{1-3}$.

Mucho antes de que entrara en funciones dicha Comisión, en 1886, el coronel Bruce, examinando el contenido bacteriano de los bazos hipertróficos pertenecientes a soldados fallecidos en Malta, a causa de la enfermedad febril desconocida, descubrió unos microbios muy pequeños. Al cabo de un año, consiguió su aislamiento y cultivo, identificándolos como los agentes de la enfermedad. Los designó con el nombre de "micrococcus melitensis" (de Melitis, con que los historiadores latinos llamaban a la isla de Malta). Este hallazgo fue comprobado por Hughes, en 1887.

Así como la fiebre tifoidea tuvo en Breto-

especial. Eyre transcribió la descripción que hizo Hipócrates de un probable caso de dicha enfermedad, que la padeció un paria que vivía encima del templo de Diana, en Thasos, el cual murió a consecuencia de la misma después de ciento veinte días de evolución ${ }^{1}$.

En 1886, Nocard, estudiando los anexos fetales de los bovinos, descubrió un micrococo que sólo en 1896 fue identificado como el agente causante del aborto epizoótico de los bovinos. El aislamiento e identificación de dicho microbio fueron conseguidos en ese último año, por el veterinario danés Bang, en colaboración con Stribolt, denominándosele “abortus bacillus". A principio del siglo XX se creía que el bacilo de Bang carecía de poder patógeno para el hombre y fue preciso llegar al año 1920 para encontrar en la literatura médica de los países del centro y norte de Europa, comunicaciones sobre la existencia en ellos de una enfermedad con

nneau, al hombre que permitió su individualización, la fiebre de Malta fue considerada como entidad nosológica por Marston, en 1863 , catorce años antes de que Bruce descubriera su agente, denominándola Mediterraneam remittent or gastric remittent fever, separándola de otras pirexias ${ }^{2}$.

Según Eyre, si alguien tuvo una idea de la fiebre de Malta antes del siglo XIX, éste fue el genial Hipócrates. La Historia de la Medicina no habla de médico alguno que durante los numerosos siglos intermedios entre aquél y la época contemporánea hubiera tenido noción más o menos exacta de esta fiebre fiebre ondulante que se observó principalmente en sujetos relacionados con el ganado bovino, análoga a la fiebre mediterránea de Malta ${ }^{2,3}$.

El hallazgo fundamental para el conocimiento de la brucelosis fue logrado en 1918, por Alice Evans, bacterióloga norteamericana, la cual en el curso de investigaciones comparativas que realizaba entre el "micrococcus melitense de Bruce" y el "abortus bacillus de Bang", comprobó la semejanza casi idéntica entre estos microbios, desde el punto de vista morfológico, inmunológico y de cultivo. Meyer y Shaw en 1920 propusie- 
ron englobar ambos microorganismos con el término común de Brucella, en honor del descubridor de uno de ellos, Sir David Bruce, constituyendo el género bacteriano que lleva dicho nombre.

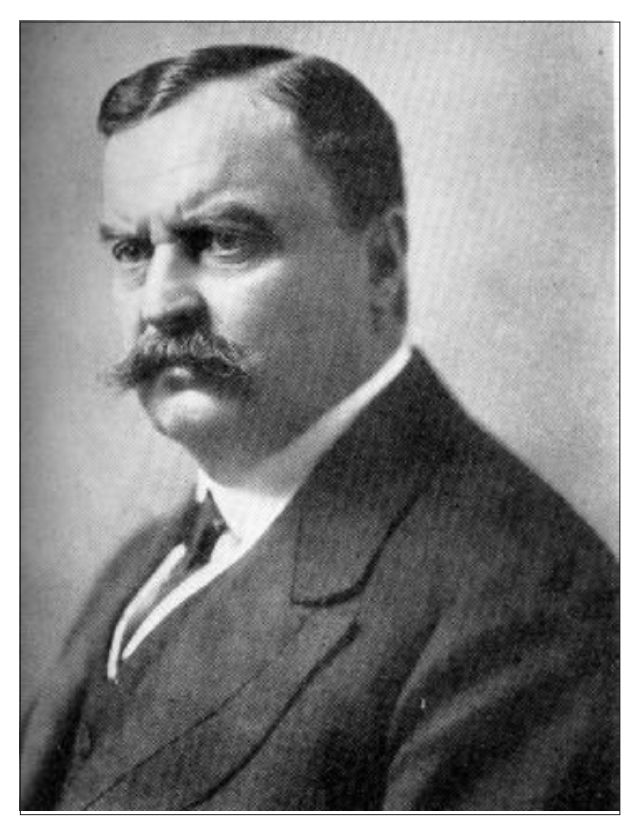

Sir David Bruce 1855-1931

En 1914, el californiano Traum, encontró en la placenta de las cerdas afectas de aborto contagioso, un microbio similar al bacilo de Bang, al que denominó "bacteria abortus suis" y que después del descubrimiento de Alice Evans, pasó a formar parte del género Brucella con el nombre de Brucella suis ${ }^{1-3}$.

En opinión de los unicistas, no existe un tipo de brucela para cada especie animal y sí en cambio, un solo género de brucelas que por su gran poder de adaptación invade al hombre y a varios animales. En el organismo de estos últimos -cabra, vaca o cerdo- adquiere caracteres que luego sirven para reconocer su presencia mediante delicadísimas técnicas establecidas por Huddlesson y que han sido aceptadas por la mayoría de los autores ${ }^{1,4}$. Si bien cada especie de brucela tiene un hospedero predilecto, las especies animales pueden padecer infecciones por una brucela que no les es habitual (brucelosis melitensis del ganado bovino, por ejemplo). En todo caso, vale la pena señalar que
Brucella melitensis infecta casi exclusivamente a las cabras y ovejas, produciendo el aborto en los ganados vírgenes de infección anterior.

Las enfermedades causadas por las brucelas han recibido múltiples denominaciones, de las que anotamos algunas: brucelosis melitocóccica o fiebre ondulante de Malta, brucelosis mediterránea, fiebre de origen caprino; brucelosis bangiana o enfermedad de Bang, fiebre ondulante bovina, brucelosis porcina o suis, fiebre ondulante porcina, enfermedad de Traum. Fueron abandonadas las con nombres de determinadas localidades en las que eran frecuentes (fiebre de Gibraltar, de Chipre, de Creta, de Corfú, de Barcelona, etc).

Desde hace años, casi todo el mundo emplea el nombre único de brucelosis, que abarca la totalidad de las enfermedades animales y humanas determinadas por el género Brucella ${ }^{1-3}$.

Es una zoonosis que afecta a los mamíferos, ocasionalmente a los humanos, sobre todo a aquellos que viven, trabajan, están en contacto o ingieren productos de los animales infectados (leche, queso, carne, sangre, orina, etc). Del mismo modo que la fiebre tifoidea, es una septicemia cíclica, que la adquiere el Hombre a través de la piel, por contacto directo de productos contaminados o ingestión; también por la mucosa respiratoria (inhalación de polvo con brucelas) o conjuntival (durante la atención de abortos de animales enfermos o por accidente en laboratorios bacteriológicos donde se trabaja con brucelas). La mucosa genital es de importancia en la transmisión de la enfermedad entre los animales. El cuadro clínico se caracteriza por fiebre ondulante (sobre todo en la forma sub-aguda), junto con hepatoesplenomegalia, mialgias, sudoración, artralgias y artritis, especialmente de columna cervical y lumbar; adenopatías y compromiso moderado del estado general.

Después de un período variable, en 15 a $20 \%$ de los enfermos no tratados y sólo en 8 al $10 \%$ de los tratados, pueden producirse recaídas. En alrededor de $10 \%$ es posible comprobar complicaciones (meningitis, encéfalo-mielitis, orqui-epididimitis, etc) $\mathrm{La}$ letalidad es baja (2 a 3\%). En algunos enfermos, a veces en plazos muy alejados del cuadro inicial no se puede demostrar una evidencia objetiva de enfermedad activa. Sin embargo, siguen manifestando molestias que en conjunto se denominan "brucelosis crónica", que se caracterizan por malestar, astenia profunda, trastornos de tipo neurótico o dispéptico, "neuralgias", impotencia sexual, etc. Para algunos el término de "brucelosis crónica" es objetable, ya que la persistencia de la sintomatología generalmente se debería a la aparición de complicaciones ${ }^{5-7}$.

Los métodos automatizados de hemocultivos y los de lisis-centrifugación presentan un buen rendimiento para el diagnóstico de laboratorio, en muestras de sangre y médula ósea. Su desarrollo es lento, requiriendo un mínimo de tres semanas. En la infección aguda la detección de $\operatorname{IgM}$ específica es útil hasta aproximadamente 3 meses del comienzo de la enfermedad. En la etapa crónica se recomienda la detección de $\mathrm{IgG}$, que se eleva (mayor de 1/160), a partir de la tercera semana. Los métodos utilizados son aglutinación en tubo (reacción de Wright'Huddlesson), que es una técnica sensible, específica y el ensayo inmuno-enzimático (ELISA). Existen exámenes cutáneos, que se basan en la inyección intradérmica de antígeno brucelósico (prueba de la melitina o brucelina) produciéndose una reacción local de hipersensibilidad con eritema, edema e induración (intradermorreacción de Burnet). La reacción positiva tiene poco valor diagnóstico ya que no permite diferenciar los enfermos de los sólo infectados ${ }^{8}$.

En Chile, la brucelosis es básicamente una zoonosis que afecta a bovinos y caprinos de algunas regiones montañosas del centro y norte del país. En la actualidad los casos clínicos son infrecuentes y aislados, pero es posible que algunos escapen a la sospecha diagnóstica, pasando inadvertidos ${ }^{5}$.

La historia de la fiebre ondulante del país parece ligada íntimamente a los progresos de la técnica bacteriológica9 .

En 1931, los doctores Hernán Alessandri y Felipe González, dieron cuenta en la Sociedad Médica de Santiago de Chile, del primer caso comprobado en el país. El microorganismo aislado en la sangre fue estudiado por el profesor Wollmann, relatando que se trataba de una brucela "posiblemente de la variedad melitense" (en 1935, en las actas de la Sociedad de Biología se indicó que aquel 
microorganismo fue aglutinado por suero anti-melitocóccico a título límite y por otra parte, el suero de dicho paciente había aglutinado al Micrococcus melitensis). En 1930 según lo menciona el doctor Enrique Onetto, en una de las empleadas del laboratorio del Instituto Bacteriológico de Chile se produjo un caso accidental de brucelosis, aislándose por medio de hemocultivo, la Brucella abortus de Bang, que correspondería al primer enfermo en Chile con brucelosis Bang, cuya evolución clínica fue larga, mejorando en forma espontánea ${ }^{10,11}$.

A raíz de la comunicación de los doctores Alessandri y González, el 17 de octubre de 1931, la Sociedad Médica acordó elevar a la Dirección General de Sanidad, el siguiente voto aprobado en asamblea con las firmas del Presidente y del Secretario, profesores Prunés y Garretón, respectivamente y que en parte decía: "la Sociedad Médica se hace un deber señalar a esa Dirección su deseo en el sentido de que las investigaciones correspondientes ya comenzadas, según lo ha expuesto el profesor Enrique Onetto, se lleven hasta su completa finalización, con el objeto de formarnos un criterio exacto acerca de la frecuencia que en realidad existe de estas infecciones entre nosotros. El hecho tiene hoy dia gran actualidad, pues esta Corporación ha sabido que algunos autores argentinos estiman que el estado epidémico que existe en Mendoza se debe a que los portadores de gérmenes provienen de Chile. Ante esta afirmación, que aparece como contradictoria con la ausencia casi absoluta de estas infecciones entre nosotros (los casos comprobados no pasan de dos), cree la Sociedad Médica que una investigación minuciosa al respecto es absolutamente necesaria" 12 .

Las primeras investigaciones para demostrar la existencia de brucelosis en el ganado caprino y en las personas cuidadores de las majadas en la región del Cajón del Maipo, en 1931, así como las efectuadas en 1933 en Atacama y Coquimbo, en 400 y 7.780 caprinos, respectivamente, fueron totalmente negativas. Sin embargo, en 1934, un nuevo estudio, en la región llamada Manzanito del Cajón del Maipo, permitió encontrar las primeras reacciones positivas, en 43 cabras de 1.595, continuando según el doctor Enrique Onetto, las experiencias para obtener el ais- lamiento del microorganismo. Todo esto permitió asegurar en forma definitiva que en Chile existía la infección melitocóccica, planteándose la posibilidad de que la bacteria hubiera llegado desde la Argentina, sin poder descartar la infección autóctona desde hacía muchos años. "Afirma Onetto, que en la historia de la epidemiología de la fiebre de Malta, nunca se ha hablado de epidemia. En Argentina no se han registrado más de 300 casos, en cinco años, en un total de 12 millones de habitantes" ${ }^{\text {13-15. }}$.

A partir de la década del 30, comienzan a aparecer en la literatura médica nacional, comunicaciones esporádicas de casos de brucelosis. La mayoría por Brucella melitensis y unos pocos por Brucella abortus de Bang. También de 3 enfermos con brucelosis suis (el último en 1962) ${ }^{16-21}$.

Durante el año 1939, fueron diagnosticados 33 casos de brucelosis humana, confirmados por la reacción de WrightHuddlesson, en Calama, Chuquicamata y pueblos vecinos, aislándose la especie melitocóccica en 3, no encontrándose Brucella abortus o suis $^{22}$.

Convendría destacar el análisis de 16 enfermos efectuado por Hernán Alessandri y Elíseo Concha, internados en el Hospital del Salvador de Santiago, entre 1938 y 1943, en que se detalla el cuadro clínico y complicaciones, mencionándose las espondilitis, orqui-epididimitis y meningo-encefalitis. Con la excepción de una mujer, todos fueron hombres, provenientes en su mayoría de poblados ubicados en el Cajón del Maipo, consumidores de leche o queso de cabra, 15 padecieron de brucelosis melitensis y uno de enfermedad de Bang ${ }^{23}$.

En 1936, los derivados de la sulfamida fueron introducidos en la terapéutica de la fiebre ondulante, con resultados que prometían ser satisfactorios. En Chile, la enfermedad que alcanzó su acmé a manera de "pequeña epidemia" durante los años 1935 y 1936, sólo dio lugar a casos aislados que no permitieron formar un juicio definitivo sobre estos fármacos. Horwitz, Kraljevic y Perroni, señalaron la buena influencia de la sulfapiridina (Dagenan $\left.{ }^{\circledR}\right)$, sobre la curva febril, hiperplasia hepato-esplénica, además del estado de confusión mental, en una niña de 13 años, que ingresó en aquella época al Servicio de Medicina y Enfermedades Infec- ciosas del Hospital Ramón Barros Luco, con una brucelosis de 15 días de evolución ${ }^{24}$.

De los enfermos señalados por Alessandri y Concha, sólo 10 recibieron ya sea sulfanilamida, sulfapiridina o sulfatiazol, utilizándose en algunos, 2 de los medicamentos alternadamente. En 7 el tratamiento coincidió con la normalización definitiva de la temperatura, pero en 3 se debió a la curación espontánea de la enfermedad.

Concluyeron que, si bien en la literatura extranjera son muchas las observaciones citadas como de valor positivo de estos medicamentos en el tratamiento de la brucelosis, también han sido publicados fracasos y recaídas ${ }^{23}$.

La asociación de estreptomicina a la terapia antedicha permitió observar una reducción del número de recaídas, así como un acortamiento del período agudo de la enfer$\operatorname{medad}^{25}$.

La introducción de cloranfenicol, tetraciclinas, etc, en el tratamiento de la infección brucelósica, dio la impresión de que el problema había sido resuelto. Sin embargo, a medida que se conoció el resultado alejado de los pacientes tratados, fue notorio el hecho que, por la magnitud de las recaídas, aún no se conseguía una solución integral para la terapia de esta enfermedad. La explicación de la dificultad para obtener una mejoría definitiva de la brucelosis debía buscarse en las características patogénicas de la afección, cuyo microorganismo, de por sí muy sensible a los antimicrobianos señalados, es capaz de localizarse estratégicamente intracelular y luego se acantona en diversos órganos con la formación de un granuloma específico. Estas etapas, intracelular e intragranulomatosa, aclararían la dificultad de los antimicrobianos para actuar frente al agente causal en concentraciones ópti$\operatorname{mas}^{6,26}$.

Entre agosto de 1950 y diciembre de 1955 ingresaron al Hospital de Enfermedades Infecciosas de Santiago de Chile 108 enfermos con brucelosis. Sólo fueron tratados 88 , ya que 20 presentaron sólo uno o dos episodios febriles, mejorando espontáneamente.

Después de su egreso fueron controlados durante plazos prudenciales. En 58 enfermos en que pudo realizarse hemocultivos, se aisló Brucella melitensis en 13 (22,4\%). La reacción de Huddlesson, practicada en 
los 88 pacientes fue positiva con títulos que oscilaron entre $1 / 200$ y $1 / 6.400$. Cincuenta eran hombres $(56,8 \%)$ y $78,4 \%$ procedía del Cajón del Maipo, con antecedentes de ingestión de leche o queso de cabra en $62 \%$. En aquella zona existía una endemia con pequeños brotes epidémicos variables. Se empleó cloranfenicol, oxitetraciclina, clortetraciclina y tetraciclina aisladamente, como única terapia en 36 enfermos, y asociados a estreptomicina en 52 . El tratamiento se mantuvo por 21 días. En general, 50mg por kilogramo de peso diario en la primera semana, $2 / 3$ de la dosis inicial en la segunda y $1 / 3$ en la tercera. La estreptomicina se utilizó en dosis de $1 \mathrm{~g}$ diario durante las tres semanas. Con la prolongación del tratamiento a 21 días como mínimo, se produjo $19,3 \%$ de recaídas. Con la terapia asociada hubo $13,4 \%$, en cambio, con el uso de un antibacteriano aisladamente, $27,7 \%$. El estudio comparativo de los resultados no permitió demostrar la superioridad de algunos en especial ni las ventajas de la asociación con estreptomicina. En todo caso, pareció que la asociación de cualquiera de las tetraciclinas con estreptomicina sería el esquema más adecuado. En esta serie de 88 pacientes fallecieron 2 enfermas $(2,2 \%)$, que recibieron cloranfenicol más estreptomicina durante 8 y 9 días, respectivamente. Una de 16 años, de forma clínica grave meningo-encefálica, con gran compromiso del estado general. La necropsia mostró focos de bronconeumonía, degeneración turbia de parénquimas, infiltración grasosa e hiperemia cerebral acentuada. La otra, de 48 años, a pesar de la mejoría transitoria de su cuadro clínico, falleció al $9^{\circ}$ día de terapia, bruscamente. En la necropsia se comprobó anemia multiorgánica, tumefacción turbia hépato-renal. El estudio histopatológico del miocardio reveló infiltrado perivascular con células mononucleares ${ }^{26}$.

H. Castro Moller, Miguel Hermosilla y colaboradores, trataron en 1951, 14 enfermos de brucelosis con cloranfenicol. A pesar de la mejoría clínica espectacular, las recaídas en 3 de ellos con producción de espondilitis y epidídimo-funiculitis, les hizo plantear un insuficiente poder del antibacteriano frente al agente causal ${ }^{27}$.

Pablo von Gerzanits, estudió 182 enfermos de brucelosis entre 1973 y 1984, en Magallanes. Utilizó en el tratamiento la com- binación de 2,5g diarios de tetraciclina más $1 \mathrm{~g}$ de estreptomicina al día durante 30 . La asociación de rifampicina en dosis de $600 \mathrm{mg}$ al día, al esquema mencionado le pareció promisoria. Sólo observó una recaída, después de 10 años de observación ${ }^{28}$.

En 1991, Carlos Hernández y Andrés Molina, publicaron el caso muy raro, de una "brucelosis localizada submandibular", en un enfermo de 29 años, manipulador de carne durante 10 , con un cuadro febril de 10 días de evolución y aumento submandibular izquierdo, mostrando la biopsia, glándula submaxilar con linfonodos de aspecto granulomatoso e infiltrado celular mixto. Reacción de Wright-Huddlesson positiva al $1 / 320$. Fue tratado con cotrimoxazol durante 8 semanas, mejorando completamente ${ }^{29}$.

La OPS preconiza actualmente, como tratamiento de elección en la brucelosis aguda y sub-aguda, rifampicina 600 a $900 \mathrm{mg}$ diarios o estreptomicina $1 \mathrm{~g}$ más doxiciclina $200 \mathrm{mg}$ al día, durante seis semanas, como mínimo. En pacientes con un cuadro tóxico y estado muy grave, sugiere utilizar corticoesteroides. Refiere un $5 \%$ de recaídas en los tratados con doxiciclina y rifampicina, las que dependerían de microorganismos "secuestrados" y no de los resistentes. El cotrimoxazol es eficaz pero las recaídas son frecuentes $(30 \%)^{30}$.

La brucelosis constituye un problema importante de salud pública, presente en todo el mundo. Provoca pérdidas económicas significativas por el daño causado a animales domésticos usados como fuente de productos cárneos y lácteos, siendo transmitida al Hombre con cierta frecuencia en áreas donde la enfermedad es enzoótica. Tanto el carbunco como la brucelosis son considerados enfermedades profesionales, lo que está contemplado en la Ley $n^{\circ} 16.744$, publicada en el Diario Oficial del día 01/02/68.

En su aspecto profesional, esta zoonosis fue abordada en nuestro país en 1939, en investigaciones referidas al personal de mataderos de Santiago y Valparaíso. En 371 trabajadores (matarifes y triperos), se encontró $12 \%$ de reacciones serológicas positivas, contrastando con $2,3 \%$ de las efectuadas en 2.002 individuos de la población hospitalaria.

La antigua Dirección de Sanidad, en conocimiento de todos los estudios clínicos y epidemiológicos practicados, creó el año 1936, una Comisión Permanente para el Estudio de la Brucelosis, compuesta de médicos, bacteriólogos y veterinarios, que conocían y habían trabajado en relación con este problema. Se pretendió, en colaboración con los diversos servicios de veterinaria, llegar a la formación de un mapa epizoo-etiológico con los diferentes focos en bovinos, caprinos, ovinos y suinos infectados. En aquella época, por razones económicas y por la poca importancia del problema humano, dado el reducido número de casos, no se continuaron muchas de las medidas adoptadas, pero es importante señalar que en el año 1987, se logró erradicar en Chile, la brucelosis melitense del ganado caprino. Sin embargo, hasta la fecha se siguen produciendo casos de brucelosis abortus Bang, tanto en el ganado bovino, como en humanos ${ }^{16,31,32}$.

En Chile, el Servicio Agrícola y Ganadero (SAG) inició el control de la brucelosis bovina en 1975, como parte del Programa Decenal de Salud Animal y en 1982 inició el Sistema de Certificación de Predios Libres de brucelosis en las regiones ganaderas IV a X. El impacto del Programa se evidenció, con la disminución de la prevalencia de la brucelosis bovina de $7 \%$ (1975) a 2,9\% (1982). No obstante, la estabilización de la prevalencia, 2,4\% en 1991, preocupó a las autoridades del SAG, razón por la cual en ese año se inició un programa de erradicación de la brucelosis bovina en el país, lo que incidió directamente sobre la ocurrencia de casos humanos. Con posterioridad al comienzo de dicho programa, las tasas disminuyeron desde $0,21 /$ 100.000 en 1991 a 0,06/100.000 en el año 2003. La prevención de la infección en el hombre depende de la profilaxis y eliminación de la enfermedad en los animales, con la vacunación del ganado bovino.

Los casos humanos de brucelosis, 9 en los años 2004 y 2005 , se han seguido presentando en forma esporádica, en las regiones VIII, X y Metropolitana. No ha habido letalidad desde $1990^{33-35}$.

\section{Referencias}

1.- Pedro-Pons A, Farreras V P. La brucelosis humana. Salvat Ed. S.A. Barcelona, España. 1944. p. 19-29.

2.- Duran de Cottes A. Fiebre de Malta. Ed. 
Morata. Madrid, España. 1941. p. 11-28.

3.- Pedro-Pons A. Patología y Clínica Médicas. Tomo VI. Enfermedades Infecciosas. Salvat Ed. Barcelona, España. 1952. pp 367409 .

4.- Brugsch Th. Tratado de Patología Médica. Tomo I. Ed. Labor S.A. Barcelona, España. 1937. pp 554-9.

5.- Brucelosis. Comité de Redacción. Bol Hosp S J de Dios 2004; 51: 192-7.

6.- Kraljevic O R, Salcedo S M. Esquemas de Enfermedades Infecciosas. Apuntes de Clases. Cátedra de Enfermedades Infecciosas, Universidad de Chile. (Desde 1950 a 1970).

7.- Kraljevic O R. Clasificación de las septicemias. Concepción etiopatogénica y Clínica. Rev Méd Chile 1992; 120: 197-201.

8.- Abarca K, García P, Vial P. Microbiología Clínica. Ed. Universidad Católica de Chile. Santiago de Chile. 2002. p. 140-1.

9.- Vaccaro H.; Horwitz A. Consideraciones inmunológicas alrededor de tres casos de fiebre ondulante. Rev Méd Chile 1938; 66: 984-7.

10.- Alessandri R H, González A F. Un caso de infección melitocóccica. Rev Méd Chile 1931; 59: 849-56.

11.- Onetto A E. Enfermedad de Bang en el hombre. Rev Inst Bact Chile 1929-1930; 1: 32-5.

12.- Prunés R L, Carretón S A. Sobre infección melitocóccica en Chile. Rev Méd Chile 1931; 9: 803-4.

13.- Vaccaro H, Onetto A E. Estudios bacteriológicos de la Fiebre de Malta. Rev
Méd Chile 1935; 63: 340-50.

14.- Vaccaro H.; Horwitz BA. La fiebre ondulante de Chile. Contribución al diagnóstico bacteriológico. Rev Méd Chile 1936; 64: 117-70.

15.- Onetto A E. Investigación sobre fiebre ondulante en Chile. Rev Inst Bact Chile 1935; 5: 31-7.

16.- Onetto E A. Resumen histórico y estado actual del problema de la brucelosis en Chile. Boletín OPS 1943, Mayo: 400-2.

17.- Onetto A E, Bradford J, Leyton G. Estudio serológico y bacteriológico de los primeros casos de fiebre ondulante diagnosticados en Chile. Rev Inst Bact Chile 1935; 5: 39-41.

18. - Miranda R, Sesnic R. Fiebre ondulante. Rev Méd Chile1938; 66: 984-7

19. - Armas C R, Acuña Z M. Dos casos de fiebre de Malta. Consideraciones generales sobre la enfermedad. Rev Méd Chile 1935; 63: 345-6

20. - Borel F H. Brucelosis suis. Rev Méd Chile 1962; 90: 521

21.- Castro D J. Un caso de fiebre ondulante. Rev Méd Chile 1946; 74: 243

22.- Onetto A E, Leyton G. La brucelosis en la provincia de Antofagasta, con especial referencia al Departamento del Loa. Rev Inst Bact Chile 1935 a 1940; 5-6-7: 37-41.

23. - Alessandri R H, Concha O E. La brucelosis humana en clínica. (Análisis de 16 observaciones). Rev Méd Chile 1943; 71: 1183-92.

24. - Horwitz B A, Kraljevic O R, Perroni B J. Sobre terapéutica con Dagenan: a) Fiebre ondulante b) Meningitis por meningococo. Rev Méd Chile 1940; 68: 934-7.
25.- Pulaski E J, Ampacher W H. Streptomycin combined with sulphonamides in the treatment of human brucellosis. Bull Army Med Dept 1947; 7: 221.

26.- Kraljevic O R, Perroni B J, Jiménez T L, Laval R E. Tratamiento de la brucelosis aguda y sub-aguda. Estudio de 88 casos. An Fac Med Sn Marcos de Lima 1959; 42: 186205.

27.- Castro M H, Hermosilla M, Rodríguez R, Bernales L, Yaníni C, Castillo Mardones S. Brucelosis y cloromicetina. Rev Méd Chile 1951; 79: 499-503.

28.- Gerzanits P. Brucelosis humana en la Región de Magallanes. Rev Méd Chile 1986; 114: 23-8.

29.- Hernández C, Molina A. Brucelosis submandibular. Rev Otorrinolaringol Cir Cabeza Cuello 1991; 51: 44-7.

30.- Chin J. El control de las Enfermedades Transmisibles. OPS. Ed. American Public Health Association. USA 2001. p. 34-8.

31.- Wall V, Zamorano C G, Paredes L A, Coyan M, Gómez J C. Prevalencia de brucelosis humana en predios agrícolas ganaderos. Comuna de Puyehue Osorno, X Región. Chile. 1999. Rev Chil Salud Pública 2000; 4: 112-6.

32.- Sánchez L M. Brucelosis humana en América. Rev Chil Infectol 1997; 14: 143-8.

33.- Ministerio de Salud. Chile. Brucelosis http:// epi mmsal.cl/epi/html/public/1998

34.- Ministerio de Salud. Chile. El Vigía 2003 $19: 40$.

35.- DEIS. Ministerio de Salud. Chile. 2006. 